\title{
Radical Polymerization of Styrene in the Presence of Ylide
}

\author{
S. Saini, A. K. Shukla, and A. K. Srivastava* \\ Department of Chemistry, Harcourt Butler Technological Institute, \\ Kanpur-208002, India
}

(Received January 29, 1985)

\begin{abstract}
The effects of $\beta$-picolinium $p$-chlorophenacylide on the solution polymerization of styrene initiated by $\alpha, \alpha^{\prime}$-azobisisobutyronitrile (AIBN), using tetrahydrofuran (THF) as an inert solvent, were investigated at 60,65 , and $70^{\circ} \mathrm{C}$. Normal kinetic features $\left(R_{\mathrm{p}} \propto[\mathrm{AIBN}]^{0.5}\left[\right.\right.$ styrene $\left.{ }^{1.0}\right)$ were observed for the AIBN initiated polymerization in the absence of ylide but in presence of ylide,

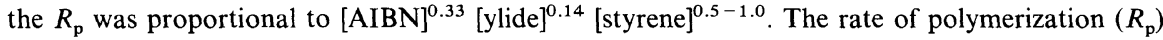
and average degree of polymerization $\left(P_{n}\right)$ increased with increasing [ylide]. The energy of activation decreased in presence of ylide. The effects of polar and non polar solvents were also studied. The accelerating effect of ylide was due to the decrease in the rate of termination $\left(R_{t}\right)$ with an increase in $P_{n}$ of the polymers with [ylide].

KEY WORDS Styrene / $\beta$-Picolinium $p$-Chlorophenacylide / Dilatometric Technique / Ubbelohde Viscometer / Acceleration / Kinetics /
\end{abstract}

Effects of various additives such as pyridine, ${ }^{1} \quad$ chlorophosphines, ${ }^{2}$ triphenylphosphite, ${ }^{3}$ phenyldiethanolamine ${ }^{4}$ on radical polymerization of styrene initiated by $\alpha, \alpha^{\prime}$-azobisisobutyronitrile (AIBN) or benzoyl peroxide have already been reported. Recently Galibei et al. ${ }^{5}$ studied the effects of nickel(II) 2-ethyl hexanoate (a) on the polymerization of styrene initiated by tertiary butyl peroxybenzoate (b) and reported that the polymerization was of the 0.42 order in $\mathbf{b}$ and 0.16 order in a. In the present communication we report the acceleration effect of $\beta$-picolinium $p$-chlorophenacylide on the radical polymerization of styrene initiated by AIBN, although we have already reported ${ }^{6}$ that this ylide initiates the radical polymerization of methyl methacrylate.

\section{EXPERIMENTAL}

Styrene (CDH make) was purified according to the method given by Overberger ${ }^{7}$ and was stored under nitrogen atmosphere in the presence of silica gel. Purified reagent grade solvents were used. $\beta$-Picolinium $p$-chlorophenacylide was prepared according to the method of $\mathrm{Krohnke}^{8}$ and Lumb. ${ }^{9}$ The AIBN was recrystallized twice with alcohol before use.

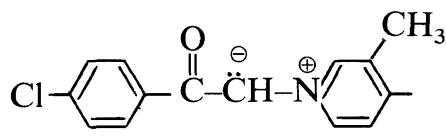

( $\beta$-Picolinium $p$-chlorophenacylide)

The polymerization reactions were carried out in a modified dilatometric apparatus ${ }^{10}$ (capillary of $2.0 \mathrm{~mm}$ diameter). The requisite amounts of ylide and AIBN were dissolved in tetrahydrofuran (THF) and the calculated amount of styrene was added to it. The solution was taken into dilatometer, which was placed in a water bath maintained at a particular temperature. The progress of the reaction was monitored with the help of a cathetometer.

\footnotetext{
* To whom all correspondence should be addressed.
} 
Polymer, precipitated with acidified methanol, was dried to constant weight.

The percentage conversion $(c)$ data were used to calculate the rate of polymerization $\left(R_{\mathrm{p}}\right)$ using the following eq $1^{10}$ :

$$
R_{\mathrm{p}}\left(\mathrm{mol} \mathrm{l} \mathrm{1}^{-1} \mathrm{~s}^{-1}\right)=\frac{1.4507 \times c \times 10^{-3}}{t}
$$

where $t$ is the polymerization time in minutes.

The intrinsic viscosity $[\eta]$ of the polymer, determined in benzene at $30^{\circ} \mathrm{C}$ by using an Ubbelohde viscometer, was used to calculate the average degree of polymerization ${ }^{11}\left(P_{n}\right)$.

$$
P_{n}=1770[\eta]^{1.4}
$$

\section{RESULTS AND DISCUSSION}

The results of kinetic investigation of the polymerization of styrene in presence of AIBN $\left(1.74 \times 10^{-2}\right.$ to $\left.5.22 \times 10^{-2} \mathrm{~mol}^{-1}\right)$ and ylide $\left(1.16 \times 10^{-3}\right.$ to $\left.23.30 \times 10^{-3} \mathrm{~mol}^{-1}\right)$ using tetrahydrofuran (THF) as an inert solvent at temperature $60-70^{\circ} \mathrm{C}$ are presented in Tables $\mathrm{I}$ and II; and Figures $1-5$.
Normal kinetic features $\left(R_{\mathrm{p}} \propto[\mathrm{AIBN}]^{0.5}[\mathrm{sty}\right.$ rene $\left.]^{1.0}\right)$ were obtained for the AIBN initiated polymerization of styrene in THF at $60^{\circ} \mathrm{C}$.

\section{Effect of the Concentration of Ylide}

The effects of [ylide] on polymerization of styrene are presented in Table I. No polymer was formed in the absence of AIBN even with $11.65 \times 10^{-3} \mathrm{~mol}^{-1}$ of [ylide]. However when AIBN initiated polymerization was carried out in the presence of ylide, the induction period of about 10 minutes was reduced to $1-2 \mathrm{~min}$ and the $R_{\mathrm{p}}$ increased gradually with increasing [ylide] up to $11.65 \times 10^{-3} \mathrm{~mol}^{-1}$ and decreased with further increase in ylide concentration. A plot of $\log R_{\mathrm{p}}$ vs. $\log$ [ylide] is fairly linear giving an exponent value with respect to [ylide] as 0.14 up to $11.65 \times 10^{-3} \mathrm{~mol}$ $1^{-1}$ of [ylide]. At high concentration of ylide, the $R_{\mathrm{p}}$ decreased, probably due to lowering of initiator efficiency which might be a consequence of high concentration of primary radicals, leading to their mutual annihilation to a certain extent. It is also clear from Table I that $P_{\mathrm{n}}$ of the polymers obtained in presence of

\begin{tabular}{|c|c|c|c|c|c|c|c|c|}
\hline \multirow{3}{*}{$\begin{array}{l}\text { Run } \\
\text { No. }\end{array}$} & \multirow{3}{*}{$\frac{[\text { Ylide }] \times 10^{3}}{\operatorname{mol~} 1^{-1}}$} & \multicolumn{3}{|c|}{$60^{\circ} \mathrm{C}$} & \multicolumn{2}{|c|}{$65^{\circ} \mathrm{C}$} & \multicolumn{2}{|c|}{$70^{\circ} \mathrm{C}$} \\
\hline & & \multirow{2}{*}{$\begin{array}{l}\% \text { Con- } \\
\text { version }\end{array}$} & \multirow{2}{*}{$\frac{R_{\mathrm{p}} \times 10^{5}}{\mathrm{~mol}^{-1} \mathrm{~s}^{-1}}$} & \multirow{2}{*}{$P_{n}$} & \multirow{2}{*}{$\begin{array}{l}\% \text { Con- } \\
\text { version }\end{array}$} & \multirow{2}{*}{$\frac{R_{\mathrm{p}} \times 10^{5}}{\mathrm{~mol}^{-1} \mathrm{~s}^{-1}}$} & \multirow{2}{*}{$\begin{array}{l}\% \text { Con- } \\
\text { version }\end{array}$} & \multirow{2}{*}{$\frac{R_{\mathrm{p}} \times 10^{5}}{\mathrm{~mol} \mathrm{1}^{-1} \mathrm{~s}^{-1}}$} \\
\hline & & & & & & & & \\
\hline 1 & 0.00 & 7.25 & 5.84 & 350.10 & 12.51 & 10.08 & 20.88 & 16.83 \\
\hline 2 & 1.16 & 7.94 & 6.40 & 438.50 & 13.42 & 10.82 & 21.50 & 17.33 \\
\hline 3 & 2.33 & 8.68 & 6.99 & 467.29 & 14.11 & 11.37 & 21.84 & 17.60 \\
\hline 4 & 3.49 & 9.24 & 7.45 & 510.20 & 15.15 & 12.21 & 22.87 & 18.43 \\
\hline 5 & 4.66 & 9.68 & 7.80 & 552.49 & 15.83 & 12.76 & 23.61 & 19.03 \\
\hline 6 & 5.82 & 9.91 & 7.99 & 571.43 & 16.12 & 12.99 & 24.15 & 19.46 \\
\hline 7 & 6.99 & 10.10 & 8.14 & 591.72 & 16.50 & 13.30 & 24.72 & 19.92 \\
\hline 8 & 8.15 & 10.46 & 8.43 & 617.28 & 16.87 & 13.60 & 25.06 & 20.20 \\
\hline 9 & 9.32 & 10.60 & 8.54 & 641.03 & 17.20 & 13.86 & 25.54 & 20.58 \\
\hline 10 & 11.65 & 11.61 & 9.36 & 806.45 & 17.74 & 14.30 & 26.28 & 21.18 \\
\hline 11 & 13.98 & 10.80 & 8.70 & - & - & - & - & - \\
\hline 12 & 16.31 & 10.31 & 8.31 & - & - & - & - & - \\
\hline 13 & 18.64 & 9.57 & 7.71 & - & - & - & - & - \\
\hline 14 & 20.97 & 9.24 & 7.44 & - & - & - & - & - \\
\hline 15 & 23.30 & 8.00 & 6.45 & - & - & - & - & - \\
\hline
\end{tabular}

Table I. Polymerization of styrene in the presence of $\beta$-picolinium $p$-chlorophenacylide in THF $^{\mathrm{a}}$

a $[$ Styrene $]=3.73 \mathrm{~mol} \mathrm{l}^{-1},[\mathrm{AIBN}]=1.74 \times 10^{-2} \mathrm{~mol} \mathrm{l}^{-1}$, polymerization time $=3 \mathrm{~h}$. 
ylide are comparatively greater than the polymers obtained in absence of ylide, and increase with increasing [ylide].

Three possible explanations may be considered for the increase in $R_{\mathrm{p}}$ :

(i) effects of ylide on the rate of decomposition of AIBN thereby effecting rate of initiation $\left(R_{\mathrm{i}}\right)$.

(ii) an increase in the rate of propagation $\left(R_{\mathrm{p}}^{\prime}\right)$ due to the formation of a complex between a monomer and ylide.

(iii) a decrease in the rate of termination $\left(R_{\mathrm{t}}\right)$.

The rates of decomposition of AIBN in THF and in THF-ylide (1:1 and $1: 2$ volume) were compared after decomposing at $60^{\circ} \mathrm{C}$ in a degassed sealed tube, by comparing the absorption at $348 \mu \mathrm{m}$ of AIBN but there was no appreciable change in the rate of decomposition of AIBN. Therefore ylide does not effect $R_{\mathrm{i}}$.

It was noted from ultraviolet and infrared analysis that the possibility of the formation of a complex between the monomer and ylide was almost nil. Therefore it may be concluded that rate of propagation is not influenced by ylide.

In order to study the effects of ylide on the rate of termination $\left(R_{\mathrm{t}}\right)$, a graph (Figure 1) between $\log R_{\mathrm{p}} / R_{\mathrm{p}}^{0}$ and $\log [\eta] /[\eta]^{0}$ was plotted $\left(R_{\mathrm{p}}\right.$ and $[\eta]$ were the rates of polymerization and intrinsic viscosity of the polymer respectively, in presence of ylide; and $R_{\mathrm{p}}^{0}$ and $[\eta]^{0}$, the corresponding values in the absence of ylide). A non-linearity of the plot suggests that termination step is effected by ylide. The increase in $P_{n}$ with [ylide] further suggests that the ylide decreases the rate of termination. ${ }^{3}$

\section{Energy of Activation}

The value of energy of activation $(\Delta E)$, for the polymerization of styrene in presence of ylide, calculated from the slope of Arrhenius plot (Figure 2) is $85.48 \mathrm{~kJ} \mathrm{~mol}^{-1}$. This value is lower than that of the value obtained in absence of ylide $\left(96.26 \mathrm{~kJ} \mathrm{~mol}^{-1}\right)$. The decrease

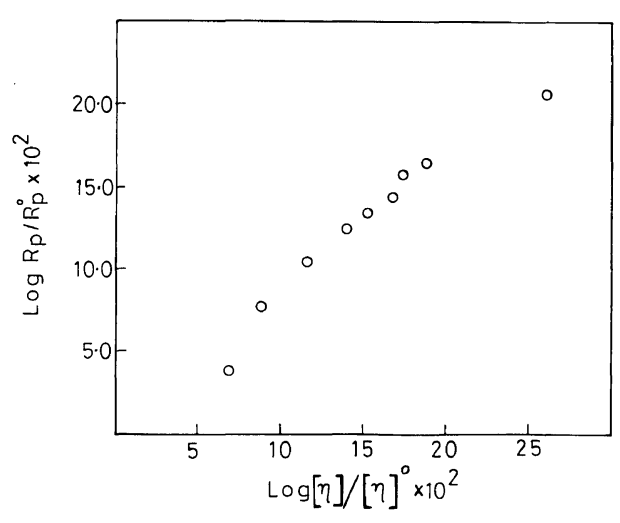

Figure 1. Plot of $\log R_{\mathrm{p}} / R_{\mathrm{p}}^{0}$ vs. $\log [\eta] /[\eta]^{0}$ for radical polymerization of styrene in presence of ylide: $[\mathrm{AIBN}]=1.74 \times 10^{-2} \mathrm{~mol} \mathrm{l}^{-1}$; [Styrene] $=3.73 \mathrm{moll}^{-1}$; polymerization temp $=60^{\circ} \mathrm{C}$; polymerization time $=3 \mathrm{~h}$.

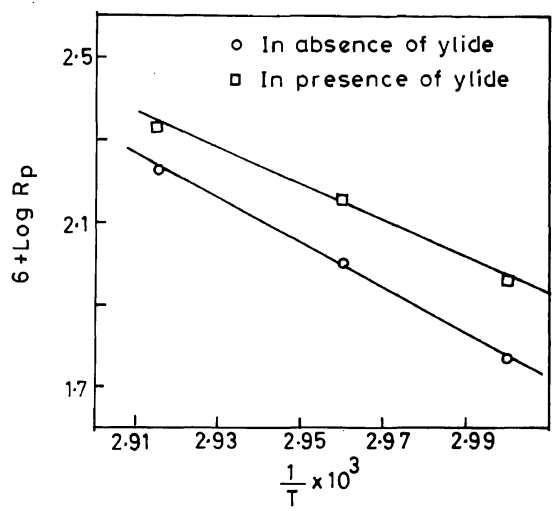

Figure 2. Relationship between log rate of polymerization and polymerization temperature: [Ylide] $=$ $11.65 \times 10^{-3} \mathrm{~mol} \mathrm{1}^{-1} ; \quad\left[\right.$ AIBN] $=1.74 \times 10^{-2} \mathrm{~mol} \mathrm{l}^{-1}$; $\left[\right.$ Styrene] $=3.73 \mathrm{moll}^{-1}$; polymerization time $=3 \mathrm{~h}$.

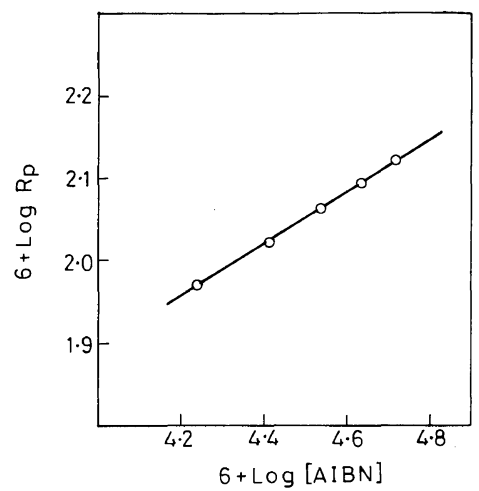

Figure 3. Relationship between $\log$ rate of polymerization and log concentration of AIBN: [Ylide] $=11.65 \times$ $10^{-3} \mathrm{~mol} \mathrm{l}^{-1}$; [Styrene] $=3.73 \mathrm{~mol} 1^{-1}$; polymerization temp $=60^{\circ} \mathrm{C}$; polymerization time $=3 \mathrm{~h}$. 


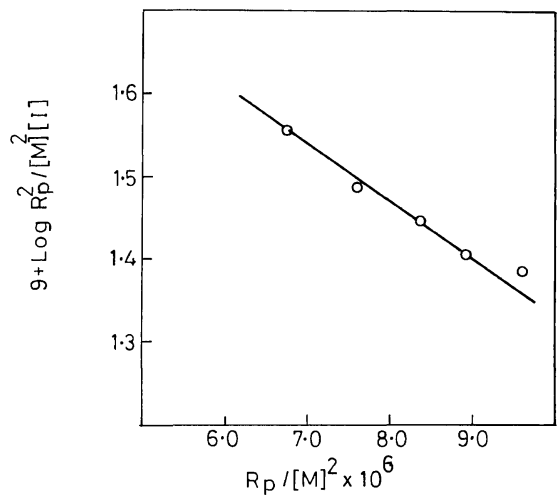

Figure 4. Plot of $R_{\mathrm{p}} /[\mathrm{M}]^{2} v s . \log R_{\mathrm{p}}^{2} /[\mathrm{M}]^{2}[\mathrm{I}]$ for radical polymerization of styrene in presence of ylide: [Ylide] $=$ $11.65 \times 10^{-3} \mathrm{moll}^{-1}$; [Styrene] $=3.73 \mathrm{moll}^{-1}$; polymerization temp $=60^{\circ} \mathrm{C}$; polymerization time $=3 \mathrm{~h}$.

in value of $\Delta E$ in the presence of ylide further confirmed the accelerating effect of ylide on polymerization of styrene.

\section{Effect of the Concentration of AIBN}

The dependence of $R_{\mathrm{p}}$ on [AIBN] was studied with varying [AIBN]; and keeping [ylide] and [styrene] constant at $60^{\circ} \mathrm{C}$. The observed dependence is $R_{\mathrm{p}} \propto[\mathrm{AIBN}]^{0.33}$ (Figure 3), which is significantly lower than the normal square root relationship.

The observed lowering in the initiator exponent value from the normal value of 0.5 may be explained in terms of primary radical termination. In fact on treatment of our experimental data according to eq 3 , given by Deb and Meyerhoff, ${ }^{12,13}$ the primary radical termination effect is significantly detectable from the negative slope of the plot $\log R_{\mathrm{p}}^{2} /[\mathrm{M}]^{2}[\mathrm{I}]$ against $R_{\mathrm{p}} /[\mathrm{M}]^{2}$ (Figure 4 ).

$$
\log \frac{R_{\mathrm{p}}^{2}}{[\mathrm{I}][\mathrm{M}]^{2}}=\log 2 f k_{\mathrm{d}} \frac{k_{\mathrm{p}}^{2}}{k_{\mathrm{t}}}-0.8684 \frac{k_{\mathrm{prt}} R_{\mathrm{p}}}{k_{\mathrm{i}} k_{\mathrm{p}}[\mathrm{M}]^{2}}
$$

where $[\mathrm{M}],[\mathrm{I}]$, and $f$ represent the monomer, initiator concentration, and initiator efficiency, respectively. The rate constants have their usual meaning, whereas $k_{\mathrm{d}}$ and $k_{\mathrm{prt}}$ are dissociation and primary radical termination

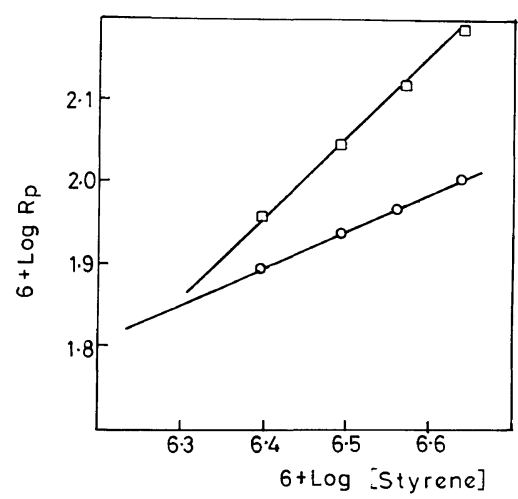

Figure 5. Relationship between log rate of polymerization and $\log$ concentration of styrene: [Ylide] $=11.65 \times$ $10^{-3} \mathrm{~mol} \mathrm{1} 1^{-1} ; \quad\left[\right.$ AIBN] $=0,1.74 \times 10^{-2} \mathrm{~mol} \mathrm{1} 1^{-1}, \square$ $5.22 \times 10^{-2} \mathrm{~mol} \mathrm{l}^{-1}$; polymerization temp $=60^{\circ} \mathrm{C}$; polymerization time $=3 \mathrm{~h}$.

constants, respectively.

\section{Effects of the Concentration of Styrene}

The polymerization of styrene using lower and higher initiator concentrations $(1.74 \times$ $10^{-2}$ and $\left.5.22 \times 10^{-2} \mathrm{~mol} \mathrm{1}^{-1}\right)$ and high [ylide] $\left(11.65 \times 10^{-3} \mathrm{~mol} \mathrm{1}^{-1}\right)$ was carried out at different monomer concentrations. The monomer exponent value, calculated from the slope of the plot of $\log R_{\mathrm{p}} v s . \log$ [styrene], is 0.5 at low initiator concentration. However the monomer exponent value becomes unity using high concentration of AIBN. The results are shown graphically in Figure 5.

\section{Effect of Additives}

The effects of polar and non polar solvents have also been studied using THF as an inert solvent (Table II). Nonpolar solvents, like carbon tetrachloride $\left(\mathrm{CCl}_{4}\right)$ and cyclohexane $\left(\mathrm{C}_{6} \mathrm{H}_{12}\right)$ enhance the $R_{\mathrm{p}}$ where as polar solvents i.e., chloroform $\left(\mathrm{CHCl}_{3}\right)$ and dimethyl sulfoxide (DMSO) have inverse effect on $R_{\mathrm{p}}$.

\section{CONCLUSION}

Thus it may be concluded that $\beta$-picolinium $p$-chlorophenacylide accelerates the polymerization of styrene by decreasing the rate of 
Radical Polymerization of Styrene in the Presence of Ylide

Table II. Effects of polar and non-polar solvents on the polymerization of styrene in the presence of $\beta$-picolinium $p$-chlorophenacylide ${ }^{a}$

\begin{tabular}{|c|c|c|c|c|}
\hline \multirow{2}{*}{$\begin{array}{l}\text { Run } \\
\text { N0. }\end{array}$} & \multirow{2}{*}{ Name of additive } & [Additive] & \multirow{2}{*}{$\begin{array}{l}\% \text { Con- } \\
\text { version }\end{array}$} & \multirow{2}{*}{$\frac{R_{\mathrm{p}} \times 10^{5}}{\mathrm{~mol} \mathrm{1}^{-1} \mathrm{~s}^{-1}}$} \\
\hline & & $\mathrm{mol} \mathrm{1}^{-1}$ & & \\
\hline \multirow[t]{4}{*}{1.} & Carbontetrachloride & 0.00 & 11.61 & 9.36 \\
\hline & & 1.48 & 13.94 & 11.23 \\
\hline & & 2.95 & 14.60 & 11.77 \\
\hline & & 4.43 & 15.24 & 12.28 \\
\hline \multirow[t]{4}{*}{2.} & Cyclohexane & 0.00 & 11.61 & 9.36 \\
\hline & & 1.45 & 14.16 & 11.41 \\
\hline & & 2.90 & 16.96 & 13.67 \\
\hline & & 4.35 & 20.87 & 16.82 \\
\hline \multirow[t]{4}{*}{3.} & Chloroform & 0.00 & 11.61 & 9.36 \\
\hline & & 1.41 & 10.73 & 8.65 \\
\hline & & 2.82 & 9.86 & 7.95 \\
\hline & & 4.24 & 9.00 & 7.25 \\
\hline \multirow[t]{4}{*}{4.} & Dimethyl sulfoxide & 0.00 & 11.61 & 9.36 \\
\hline & & 1.41 & 9.93 & 8.00 \\
\hline & & 2.82 & 8.32 & 6.71 \\
\hline & & 4.22 & 7.01 & 5.65 \\
\hline
\end{tabular}

${ }^{a}[$ Ylide $]=11.65 \times 10^{-3} \mathrm{moll}^{-1}, \quad[$ Styrene $]=3.73 \mathrm{moll}^{-1}, \quad[\mathrm{AIBN}]=1.74 \times 10^{-2} \mathrm{moll}^{-1}$, polymerization temp $=$ $60^{\circ} \mathrm{C}$; polymerization time $=3 \mathrm{~h}$.

termination.

Acknowledgement. Authors are thankful to the Director, H.B.T.I., Kanpur for providing necessary facilities. One of the authors (S.S.) is also thankful to CSIR, New Delhi for providing financial assistance.

\section{REFERENCES}

1. P. Ghosh and G. Mukhopadhyay, J: Polym. Sci., Polym. Chem. Ed., 17, 583 (1979).

2. H. Uemura, T. Taninaka, and Y. Minoura, J. Polym. Sci., Polym. Lett. Ed., 15, 493 (1977).
3. T. Taninaka, T. Ogawa, and Y. Minoura, J. Polym. Sci., Polym. Chem. Ed., 13, 681 (1975).

4. B. M. Sogomonyan, Arm. Khim. Zh., 35, 216 (1982).

5. V. I. Galibei, J. A. Andor, and I. Dreveni, Acta Phys. Chem., 27, 141 (1981).

6. A. K. Srivastava and S. Saini, J. Macromol. Sci., Chem., A22, 43 (1985).

7. C. G. Overberger and N. J. Yamamoto, J. Polym. Sci., A-1, 4, 3010 (1966).

8. F. Krohnke, Ber., 66B, 604 (1933).

9. J. T. Lumb, Tetrahedron Lett., 579 (1970).

10. A. K. Srivastava and A. K. Shukla, J. Macromol. Sci., Chem., A21, 867 (1984).

11. A. V. Tobolsky, J. Am. Chem. Soc., 74, 938 (1952).

12. P. C. Deb and G. Meyerhoff, Eur. Polym. J., 10, 709 (1974).

13. P. C. Deb, Eur. Polym. J., 11, 31 (1975). 